\title{
Bio-efficiencies of Probiotic Yoghurt and Fermented Sour Sobya Supplements on Gut Microbial Health and other Associated Health Biomarkers Among Egyptian Pre-school to School Age Children
}

Rania Bassuoni ${ }^{1}$, Magda Soliman ${ }^{1}$, Laila Hussein ${ }^{1 *}$, Mohammed T Fouad ${ }^{2}$, Mohamed A Arafa ${ }^{3}$ and Ashraf A Abd El-Meged ${ }^{3}$

${ }^{1}$ Departments of Nutrition, National research center, Giza, Egypt

${ }^{2}$ Dairy sciences, National research center, Giza, Egypt

${ }^{3}$ Department of Nutrition and Food Science, Helwan University, Cairo, Egypt

\section{Abstract}

Background: The nutritional status and diet quality of pre-school to school age children were assessed using standard dietary assessment techniques.

Design of the randomized controlled trial (RCT): The children were divided into 4 arms whereby each group consisted of 6 children. Group (1) served as control; group (2) consumed rice milk porridge and served as placebo; group (3) consumed commercial Bifido probiotic yoghurt (PY) and group (4) consumed commercial fermented sour sobya (SS) providing diverse Lactobacilli and yeasts. Stool and urine samples were collected before and after 3 week of dietary intervention.

Results: The overall weight for age Z-score (WAZ), height for age Z-score (HAZ) and weight for height $\mathrm{Z}$-score (WHZ) were within the norms (above - 0.2 ). However, $15.4 \%$ of the boys were wasted (WHZ < $-.2)$; and $54.4 \%$ of the girls were stunted $(\mathrm{HAZ}<-0.2)$. The mean ratio of the estimated energy intake $(\mathrm{EI})$ to basal metabolic rate (BMR) was unity (1:1). The dietary fat, total and animal proteins were well balanced and made up overall averages of $32.4,16.7$ and $11.17 \%$ of the total energy intake (EI), respectively and the healthy eating index (HEI) average $60.7 \pm 1.39 \%$. The 3 week dietary intervention with PY or SS improved the balance of gut resident microbiota as evidenced by significant increases in the mean counts of beneficial gut bacteria and significant reduction in the pathogenic Enterobacteriaceae. The mean concentration of secretory immunoglobulin A increased significantly in the stool of the children following 3 week consumption of the PY or SS compared with the respective pre-feeding levels. The urinary hydroxyproline index (HPRO-I), a biomarker of linear growth increased significantly among all the children consuming the PY or SS compared to the respective baseline levels. The mean levels of urinary thiobarbituric acid (TBA), a biomarker of oxidative stress were reduced significantly among the two groups consuming the fermented PY or SS.

Conclusion: PY or SS supplements are comparable in their bioefficiency as non-pharmacological biotherapeutics for a healthy gut. The 3 week daily intake of PY or SS stimulated the immune system and accelerated growth.

\section{Introduction}

According to UNICEF, WHO and the World Bank, the prevalence of stunting was reduced from $23.7 \%$ in the year 2000 down to $17.2 \%$ in the year 2018 among the children population under 5 years from North Africa [1]. Respective prevalences of moderate and severe wasting were reduced from $6.0 \%$ down to $1.6 \%$ for the same period of time. In the year 2015, leaders from 193 countries of the world came together and created the sustainable development goal 2030 [2] with a set of 17 goals. Goal number (2) aims to end hunger and malnutrition because low micronutrient intake is a particular problem in some children groups and goal (6) aims to assure the access of hygienic safe foods and drinking water to all. Because young children's immune systems are not completely mature, they need to be protected from both acute and chronic infections. Infection by dietary pathogens, possibly from unhygienic food preparation and adverse environmental factors are determinant factors causing significant overgrowth of intestinal microorganisms and their metabolites and are key players in the development of malnutrition and ill-health $[3,4]$, which are major constraints in achieving the SDG 2030 in food-insecure settings.

Adding different animal-sources to the diets of young children showed improvement in children's growth expressed as weight-for-age and height for-age Z-scores [5-7]. However, there is now concern that using milk to improve the nutritional status of Egyptian children

\author{
Publication History: \\ Received: July 09, 2019 \\ Accepted: August 27, 2019 \\ Published: August 29, 2019
}

\section{Keywords:}

Egyptian children, Z -scores, Healthy eating index,

Nutrient adequacy, Gut microbiota,

Systemic immunoglobulin, A-Hydroxyproline index Urinary thiobarbituric acid is problematic because of the high prevalence of lactose intolerance [8]. The use of dietary supplements (DS) containing probiotics has been increasing in most nations, with the major reason for the improvement of the overall gut health of children. Selected strains of Bifidobacterium spp and Lactobacilli (Lactic acid bacteria) are the main strains with proven probiotic effects [9]. The ability to survive in the gastrointestinal environment is recognized as a fundamental requisite for probiotics [10]. To produce health benefit to the host, the recommended minimum orally ingested dose for a potential effect of live probiotic bacteria per $\mathrm{g}$ of product ranged between $10^{8}$ to $10^{12}$ colony-forming units (cfu) per day equivalent to 0.1 up to 100 billion cfu per day [11-14]. The functional aspects of probiotic action in terms of functionality and efficacy are mostly related to the concept of the targeted microbial generation of functional molecules, such

"Corresponding Author: Prof. Laila Hussein, Departments of Nutrition, National research center, Giza; E-mail: dr.lailahussein@yahoo.com

Citation: Bassuoni R, Soliman M, Hussein L, Fouad MT, Arafa MA, et al. (2019) Bio-efficiencies of Probiotic Yoghurt and Fermented Sour Sobya Supplements on Gut Microbial Health and other Associated Health Biomarkers Among Egyptian Pre-school to School Age Children. Int J Clin Nutr Diet 5: 145. doi: https://doi. org/10.15344/2456-8171/2019/145

Copyright: (c) 2019 Bassuoni et al. This is an open-access article distributed under the terms of the Creative Commons Attribution License, which permits unrestricted use, distribution, and reproduction in any medium, provided the original author and source are credited. 
Citation: Bassuoni R, Soliman M, Hussein L, Fouad MT, Arafa MA, et al. (2019) Bio-efficiencies of Probiotic Yoghurt and Fermented Sour Sobya Supplements on Gut Microbial Health and other Associated Health Biomarkers Among Egyptian Pre-school to School Age Children. Int J Clin Nutr Diet 5: 145. doi: https:// doi.org/10.15344/2456-8171/2019/145

Page 2 of 11

as bioactive peptides, during food fermentation [15]. Our previous investigation showed that dietary intervention with the probiotic Lactobacillus acidophilus La1 in yoghurt matrix restored the intestinal permeability of Egyptian children (10.5 years old) due to up regulating the intestinal permeability and lowering the fecal $\mathrm{pH}$ values [3]. The global market for probiotics used in food and beverages grow at a rate of $7.9 \%$ from $\$ 28.6$ billion in 2017 to $\$ 41.9$ billion in 2022 [16] FAO [17] encourages more extensive studies on probiotic traditional fermented foods because the acid-producing organisms in fermented dairy products could prevent "fouling" in the large intestine.

Sour sobya [SS] a traditional fermented rice milk product containing probiotic Lactobacilli [LAB] is in symbiosis with mixed yeasts spp [18]. This fermented food product had been spotlighted for its antimicrobial and antioxidative activities [19] and its functionalities on promoting different metabolic activities of the colon of adolescent boys [20]. The objective of the present study is to generate adequate dietary intervention data and establish differences in relative efficacy of probiotic yoghurt, with proven probiotic strains originating from the West and of the fermented SS rich in indigenous probiotic bacteria strains. Criteria of efficacy included gut microbiota composition, secretory immunoglobulin A, biomarkers of growth and oxidative stress.

\section{Children and Methods}

\section{Design of the Study}

The research protocol and all informed consent documents were approved by the NRC Medical Research Ethics Committee (MREC 13-125). Informed written consent was obtained from the mother of each child after a thorough explanation of the study details.

All children were living in urban Giza, whose parents were university graduates and the children were attending day care centers or primary schools. Criteria for inclusion was the age of the children in the range between 3 - 9 years; with no problems of gastrointestinal absorption, no use of antibiotics during the last three months prior to the study; the taste of the supplement was acceptable to the child; the mother was willing to collect stool and urine samples at predetermined dates.

\section{Randomized controlled trial (RCT)}

Twenty four children were assigned randomly into a 4-arm diet intervention trial with 6 children per group. Control group hadn't receive any supplement; Placebo group had been consuming daily 140 g rice milk porridge; 3 - Probiotic yoghurt (PY) had been consuming daily $135 \mathrm{~g}$ (1.5 cup) commercial probiotic yoghurt (PY) and Sour sobya (SS) had been consuming daily $140 \mathrm{~g}$ commercial fermented sour sobya. The children were home visited daily by a qualified nutritionist for distributing the assigned supplement and for observing and recording compliance.

\section{Supplements}

The probiotic yoghurt was purchased in sealed cups weighing $90 \mathrm{~g}$ each, containing Bifidobacterium animalis lactis DN-173 010/CNCM I-2494 strain [Activia] Sour sobya (SS). (Elrahmany, Sayeda Zeinab, Cairo) was purchased twice a week in $500 \mathrm{~g}$ container and saved in the refrigerator. Sour sobya (SS) is traditional fermented rice based porridge containing diverse Lactobacilli and Saccharomyces cerevisae with added milk powder, sugar, grated coconut and seasonings. The product is a favorite dessert with sweet sour flavor and is consumed by a considerable segment of the population. Commercial rice milk porridge was purchased from the retail market in 140 gsealed containers.

\section{Baseline Characteristics of the Children}

Data collected at base line included anthropometric measurements; dietary assessments, collection of stool and urine samples.

Anthropometric measurements were recorded by trained staff according to standard procedures. The age of the child was obtained from the birth certificate; Body weight and standing height measurements were taken, while the child was with the light clothes and bare footed. Based on the data on age, sex, body weight and height for each child, the respective 3 nutrition indices of physical growth; weight for age $Z$ score (WAZ), height for age $Z$ score (HAZ) and weight for height $\mathrm{Z}$ score (WHZ) were computed by the EPI INFO software program (CDC). The child whose WAZ measures is below minus two (WAZ <-2) is underweight for his age. The HAZ index identifies linear growth and the child whose HAZ is below (2.0) from the WHO child growth standards reference population is considered short for his age, or stunted. The WHZ measures body mass in relation to body length and the child whose WHZ is below $(-2.0)$ is thin for his height [21].

The basal metabolic rate (BMR) was computed in mega joules (MJ) using the following equations [22]. Boys 3-10 years $=0.095 \mathrm{x}$ body weight +2.11 , Girls 3 - 10 years $=0.085 \mathrm{x}$ body weight +2.03 . The BMR was expressed in kcal from the relation $1 \mathrm{Mj}=4180 \mathrm{kcal}$.

\section{Dietary intake data}

Usual dietary intake of food groups and nutrients was estimated by collecting three 24-hour dietary recalls on nonconsecutive days from the mother of each child. The mothers recalled all foods and beverages consumed by their child during the previous 24 hours (beginning from morning meal on the day before up to the morning meal on the day of the interview). All mothers were then asked to estimate the quantities of the mentioned foods and to state the ingredients used for preparing the dishes and their respective quantities. To facilitate the quantity estimates, standardized household measures (cups, plates and bowls etc.) were provided by the interviewer and marked with several levels to indicate different contents. Raw ingredients were converted from household measures to weight estimates by taking reference weights, calculated on the basis of the average of weights on a digital weighing-scale. The average portion sizes consumed in grams of each food composite were converted into the respective estimated daily energy and nutrient intakes by using the Egyptian precise food composition table. The total healthy eating index (HEI-2015) is an overall diet quality assessment tool and it is scored from 0 to 100 [23]. It consists of 13 components including 9 adequacy components (total fruit; whole fruit; total vegetables; greens and beans; whole grains; dairy; total protein foods; seafood and plant proteins; and fatty acids and each ranged from 0 to 5 or 0 to 10 points. Lower scores indicate suboptimal intake for which higher scores reflect higher intakes. Moderation components included refined grains, sodium, and added sugar for which higher scores reflected lower intakes. Children who did not consume any servings of the food groups received zero score and partial consumption resulted in proportional deduction of points and higher scores indicated higher intakes. HEI 2015 total sub-score and component scores were calculated for each day of the 3 collection days. 
Citation: Bassuoni R, Soliman M, Hussein L, Fouad MT, Arafa MA, et al. (2019) Bio-efficiencies of Probiotic Yoghurt and Fermented Sour Sobya Supplements on Gut Microbial Health and other Associated Health Biomarkers Among Egyptian Pre-school to School Age Children. Int J Clin Nutr Diet 5: 145. doi: https:// doi.org/10.15344/2456-8171/2019/145

Page 3 of 11

\section{The estimated average nutrient requirement (EAR)}

The food intake data were converted into weights and the combined data were converted into respective energy and the estimated nutrient intakes was calculated using the data values from the precise Egyptian food composition table using a computer aided nutritional analysis program. The probability of nutrient adequacy (PA) was calculated by comparing the actual intake with indices used to evaluate the overall nutritional quality of the children diets. The age and sex-specific FAO/ WHO essential minerals and vitamins [24] were used as reference for expressing the individual daily intake of a nutrient into the respective probability of nutrient adequacy (PA). The requirement for zinc was based on medium bioavailability [24]. The percentage of reference for each nutrient was capped at $100 \%$ daily value (DV) to avoid overvaluing by single nutrient. Validation test. Ratios of estimated daily energy intake (kcal) / BMR (kcal) below 0.5 were excluded from the calculation.

\section{Microbiological examination and enumeration}

Culture media for the enumeration of Bifidobacterium in the presence of yogurt bacteria was prepared according to Antunes et al [25]. The plates were incubated in anaerobic conditions at $37^{\circ} \mathrm{C}$ for $48-72 \mathrm{~h}$, after which LAB colonies in each plate were counted. The results are expressed as the $\log _{10}$ cfu per gram of probiotic yoghurt. The viable Lactobacilli in the SS was carried out by serial dilutions of SS from $1 / 10$ to $1 / 10^{7}$ and plating $100 \mu$ aliquots on the selective MRS agar media (de Man, Rogosa and Sharpe; Difco, Sparks, MD, USA) supplemented with $3 \%$ ethanol and $0.5 \%$ cycloheximide to inhibit yeast growth [26]. The plates were incubated at $37^{\circ} \mathrm{C}$ under anaerobic environment using anaerobic gas packs (Oxoid, Uni path Ltd, Basing stoke, UK), capable of producing $1800 \mathrm{~cm}^{3}$ hydrogen and $350 \mathrm{~cm}^{3}$ carbon dioxide and examined after 5 days for the bacterial growth and the counts were expressed as CFU/gram SS. Eight Lactobaccilli colonies (Gram positive isolates) were isolated from the highly diluted plates and were further identified by matrix-assisted laser desorption/ ionization time-of-flight mass spectrometry (MALDI-TOF MS) protein analysis. The method had been described earlier in detail by many investigators [27-29]. The yeasts in SS were enumerated on acidified yeast extract $10 \mathrm{~g}$; peptone $20 \mathrm{~g}$; glucose $20 \mathrm{~g}$; agar $15 \mathrm{~g}$ per liter [YEPG] adjusted to $\mathrm{pH}$ 3.5. The plates were incubated at $30^{\circ} \mathrm{C}$ for $72 \mathrm{~h}$ and colonies were enumerated and the yeast isolates were identified with API 50 CHL test (BioMerieux, Marcy-l'Etoile, France) following instructions of the manufacturer.

\section{Fecal microbiological examination and enumeration}

Baseline fecal collection was performed within 24 hours before the beginning of the RCT and the $2^{\text {nd }}$ stool collection was completed by last day of the RCT. The children evacuated their feces into containers and the mothers were asked to save them on ice until transported to the laboratory for bacterial count. The microbiological testing was completed within 24 hours of stool collection and the remaining stool sample was kept frozen at $-20^{\circ} \mathrm{C}$ for further analysis.

Ten grams of stool sample were mixed with $90 \mathrm{ml}$ of sterile physiological saline $(8.5 \mathrm{~g} \mathrm{NaCl} / \mathrm{l})$ to make an initial dilution of one tenth (1/10).The suspension was used for making suitable serial dilutions up to $10^{-8}$ by incorporating $1 \mathrm{ml}$ into $9 \mathrm{ml}$ of saline in sterile tubes and vigorous mixing. Aliquots $(100 \mu \mathrm{l})$ of each dilution were subsequently plated on the following selective medias: Total anaerobic bacteria (Columbia blood agar; Bio Mérieux ); Bacteroides (Bacteroides Bile Esculi); Bifidobacteria were grown on modified Beerens Columbia agar base + cysteine [30]; Enterobacteriaceae on MacConkey broth (BGMB); Lactobacilli on anaerobic deMan-Rogosa-Sharpe (MRS) agar with vancomycin [31]. The plates were incubated at $37^{\circ} \mathrm{C}$ for 3 days under anaerobic conditions using Gas Pak $\left(\mathrm{H}_{2}\right.$ and $\left.\mathrm{CO}_{2}\right)$ anaerobic systems (BBL Microbiology Systems, USA). The colonies were counted and expressed as $\log _{10}$ colonies forming unit (CFU) per gram fecal material. Yeasts and molds were enumerated on pour plates of potato dextrose agar, PDA (Oxoid, UK). The plates were incubated at $25^{\circ} \mathrm{C}$ for 5 days. The colonies on the plates were counted (CFU), and the numbers were expressed as $\log _{10}$ cfu per $\mathrm{g}$ fecal material.

Assay of stool secretory immunoglobulin A (s-Ig A). The Immu Chrom ELISA kit (Bio Vender research Diagnostics, Cat \# RIC 6100 , Germany) was used and the instruction of the manufacturer was followed. Weighed portions $(80-120 \mathrm{mg}$ ) were diluted, vortexed and centrifuged at $13000 \mathrm{rpm}$ for 5 minutes. The supernatant was diluted 1:250 in wash buffer. Standards, controls and stool samples were simultaneously run in the ELISA and the concentration of s-IgA was read at $405 \mathrm{~nm}$ in ELISA reader against a standard curve and the results were expressed in mg per gram stool.

\section{Urine collection}

First urine collection was performed within 24 hours before the beginning of the RCT (baseline) and the second urine sample was collected at the end of the 3 week RCT. The children were asked to evacuate morning urine into containers and aliquots were immediately frozen at $-20^{\circ} \mathrm{C}$ until further analysis.

\section{Urinary Total Hydroxyproline (HPRO)}

The total urinary Hydroxyproline was determined by acid hydrolysis by mixing urine aliquots $(100 \mu \mathrm{l})$ with equal volume of 12 normal hydrochloric acid in air tight screw pyrex tubes and the tubes were heated at $125^{\circ} \mathrm{C}$ for $2 \mathrm{~h}$. Upon cooling the $\mathrm{pH}$ of the acid hydrolysate was adjusted to 6.0 by sodium carbonate / citrate /1- isopropanol buffer solution. The decolorization with active charcoal; the formation of pyrole derivative with tosylchloramine and the development of the color with p- aminobenzaldehyde (Ehrlich's reagent followed the standard method [32]. The intensity of the developed pink color was recorded at $560 \mathrm{~nm}$ against a blank. The results are expressed as $\mu \mathrm{g}$ total HPRO per ml urine.

Urinary creatinine was determined by the classical alkaline picric acid - sodium hydroxide reagent $[33,34]$.

Urinary Hydroxyproline creatinine ratio (HPRO) The urinary hydroxyproline is expressed as total hydroxyproline / creatinine $(\mathrm{mg} / \mathrm{g})$. The Hydroxyproline index [HPRO-I] is defined as Hydroxyproline creatine ratio/per kg body weight.

Determination of urinary thiobarbituric acid [U-TBA]. The colorimetric method was followed using the TBA reaction [35] and the results were expressed as urinary TBA creatinine ratio $(\mathrm{mg} / \mathrm{g})$.

\section{Statistical Analysis}

All data were expressed as the arithmetic means with standard error. The data were examined for the total sample of children as well as stratified by gender and by two distinct age groups: $<6$ years 
Citation: Bassuoni R, Soliman M, Hussein L, Fouad MT, Arafa MA, et al. (2019) Bio-efficiencies of Probiotic Yoghurt and Fermented Sour Sobya Supplements on Gut Microbial Health and other Associated Health Biomarkers Among Egyptian Pre-school to School Age Children. Int J Clin Nutr Diet 5: 145. doi: https:// doi.org/10.15344/2456-8171/2019/145

Page 4 of 11

and school-age children $\geq 6$ years. Numerical data were presented in Whisker box plots showing median and interquartile ranges. Paired t-test was used to compare within groups between baseline and subsequent to treatment. Treatments were examined for significance by one way ANOVA followed by Duncan test. Pearson correlation coefficients were computed and $\mathrm{P}=0.05$ indicates significant statistical differences. SPSS version 18 software program and Excel sheet were used for the statistical analysis.

\begin{tabular}{|c|c|c|c|c|c|c|}
\hline Parameter & All children $(\mathrm{N}=24)$ & Boys & Girls & Age $<6$ years & Age $\geq 6$ years & Norms \\
\hline Age, mo & $80.3 \pm 2.8$ & $80 \pm 3.7$ & $83 \pm 4.6$ & $51 \pm 3.5$ & $95.4 \pm 1.34$ & \\
\hline HAZ & $-0.79 \pm 0.18$ & $0.1 \pm 0.17^{b}$ & $-1.8 \pm 0.22^{\mathrm{a}}$ & $-1.05 \pm 0.38^{a}$ & $-1.82 \pm 0.22^{\mathrm{a}}$ & $>-2.0$ \\
\hline WAZ & $-0.20 \pm 0.24$ & $-0.17 \pm 0.36$ & $-0.23 \pm 0.33$ & $-1.0 \pm 0.42$ & $0.18 \pm 0.25$ & $>-2.0$ \\
\hline WHZ & $0.54 \pm 0.31$ & $-0.27 \pm 0.43^{a}$ & $1.5 \pm 0.18^{b}$ & $-0.55 \pm 0.64^{a}$ & $1.1 \pm 0.24^{\mathrm{b}}$ & $>-2.0$ \\
\hline BMR, kcal & $973 \pm 22$ & $1017 \pm 35$ & $936 \pm 29$ & $783 \pm 32$ & $1071 \pm 19$ & \\
\hline EI, kcal & $910 \pm 38$ & $878 \pm 50$ & $946 \pm 59$ & $732 \pm 46$ & $993 \pm 47$ & \\
\hline EI/ BMR & $0.94 \pm 0.04$ & $0.88 \pm 0.05$ & $1.01 \pm 0.06$ & $1.0 \pm 0.07$ & $0.93 \pm 0.04$ & \\
\hline HEI (maximum 100 points) & $60.7 \pm 1.4$ & $61.3 \pm 2.0$ & $60.0 \pm 2.0$ & $57.7 \pm 2.1$ & $62.3 \pm 1.8$ & 80 \\
\hline Protein, g/d & $37.5 \pm 1.8$ & $36.2 \pm 2.5$ & $39.0 \pm 2.6$ & $29.6 \pm 2.6$ & $41.2 \pm 2.2^{b}$ & \\
\hline Animal prot, g/d & $19.2 \pm 1.6$ & $18.5 \pm 2.3$ & $20.0 \pm 2.3$ & $16.2 \pm 2.5$ & $20.6 \pm 2.0$ & \\
\hline Fat, g/d & $32.4 \pm 1.6$ & $30.1 \pm 2.1$ & $35.0 \pm 2.3$ & $30.0 \pm 2.4$ & $33.6 \pm 2.0$ & \\
\hline Satur fat, g/d & $17.7 \pm 1.1$ & $16.6 \pm 1.4$ & $19.0 \pm 1.7$ & $15.2 \pm 2.0$ & $18.8 \pm 1.3$ & \\
\hline $\mathrm{M}+\mathrm{P}$ unsat fat, $\mathrm{g} / \mathrm{d}$ & $14.7 \pm 1.0$ & $13.6 \pm 1.4$ & $16.0 \pm 1.51$ & $14.4 \pm 1.4$ & $14.8 \pm 1.4$ & \\
\hline Protein ,\% EI & $16.7 \pm 0.58$ & $16.5 \pm 0.78$ & $16.8 \pm 0.86$ & $16.4 \pm 1.2$ & $16.8 \pm 0.64$ & \\
\hline Animal prot,\% EI & $8.7 \pm 0.66$ & $8.6 \pm 0.95$ & $8.7 \pm 0.93$ & $9.1 \pm 1.3$ & $8.5 \pm 0.77$ & \\
\hline Fat,\% EI & $32.5 \pm 0.92$ & $31.9 \pm 1.51^{\mathrm{ab}}$ & $32.3 \pm 0.92^{\mathrm{ab}}$ & $35.9 \pm 1.2^{\mathrm{b}}$ & $31.0 \pm 1.15^{\mathrm{a}}$ & \\
\hline $\mathrm{CHO} \% \mathrm{EI}$ & $50.8 \pm 1.1$ & $51.5 \pm 1.7$ & $49.9 \pm 1.5$ & $47.7 \pm 2.0$ & $52.2 \pm 1.39$ & \\
\hline Vit A intake,\% requirement & $45 \pm 4.6$ & $42 \pm 5.9$ & $48.5 \pm 7.3$ & $50.2 \pm 8.0$ & $42.4 \pm 5.7$ & \\
\hline Vit B1 intake,\% requirement & $72.4 \pm 2.5$ & $70.9 \pm 3.6$ & $74.1 \pm 3.7$ & $76.8 \pm 4.2$ & $70.2 \pm 3.2$ & \\
\hline Vit B2 intake,\% requirement & $36.9 \pm 3.7$ & $40.4 \pm 5.2$ & $32.9 \pm 5.1$ & $37.6 \pm 6.8$ & $36.6 \pm 4.4$ & \\
\hline Vit B6 intake, \%requirement & $55.9 \pm 2.6$ & $56.9 \pm 3.2$ & $54.7 \pm 4.2$ & $55.9 \pm 2.6$ & $49.1 \pm 2.9$ & \\
\hline Vit B12 intake,\% requirement & $71.3 \pm 3.4$ & $74.9 \pm 4.5^{\mathrm{ab}}$ & $67.2 \pm 5.2^{\mathrm{ab}}$ & $84.1 \pm 5.1^{\mathrm{b}}$ & $65.0 \pm 4.2^{\mathrm{a}}$ & \\
\hline Folate intake, \% requirement & $45.2 \pm 2.2$ & $43.6 \pm 2.5^{\mathrm{ab}}$ & $47.1 \pm 3.7^{\mathrm{ab}}$ & $54.1 \pm 4.4^{\mathrm{b}}$ & $40.7 \pm 2.2^{\mathrm{a}}$ & \\
\hline Vit C intake,\% requirement & $57.5 \pm 4.1$ & $59 \pm 5.7$ & $55.7 \pm 6.1$ & $55.6 \pm 7.5$ & $58.4 \pm 5.0$ & \\
\hline Niacin intake $\%$ requirement & $71.7 \pm 2.7$ & $72.6 \pm 3.2$ & $70.7 \pm 4.6$ & $77.5 \pm 4.2$ & $68.8 \pm 3.5$ & \\
\hline Calcium intake,\% requirement & $57.3 \pm 3.1$ & $52.9 \pm 4.1$ & $62.5 \pm 4.8$ & $63 \pm 5.8$ & $54.4 \pm 3.7$ & \\
\hline Zinc intake, \% requirement & $77.9 \pm 2.7$ & $79.9 \pm 2.5$ & $75.6 \pm 2.9$ & $81.9 \pm 2.8$ & $75.9 \pm 2.6$ & \\
\hline Estimate average requirement,\% & $57.3 \pm 3.1$ & $59.3 \pm 2.1^{\mathrm{b}}$ & $58.7 \pm 2.4^{\mathrm{b}}$ & $65 \pm 2.9^{b}$ & $56.0 \pm 1.7^{\mathrm{a}}$ & \\
\hline Fecal total anaerobes, $\log _{10} / \mathrm{g}$ & $9.0 \pm 0.01$ & $9.0 \pm 0.01$ & $9.0 \pm 0.02$ & $9.0 \pm 0.02$ & $9.0 \pm 0.01$ & \\
\hline Bacteroide spp, $\log _{10} / \mathrm{g}$ & $6.1 \pm 0.57$ & $7.0 \pm 0.57$ & $5.3 \pm 1.0$ & $6.3 \pm 0.9$ & $5.9 \pm 0.74$ & \\
\hline Bifido genus, $\log _{10} / \mathrm{g}$ feces & $7.8 \pm 0.02$ & $7.9 \pm 0.02$ & $7.8 \pm 0.03$ & $7.8 \pm 0.02$ & $7.9 \pm 0.03$ & \\
\hline Enterobacteriaceae, $\log _{10} / g$ feces & $6.5 \pm 0.4$ & $7.1 \pm 0.07$ & $5.8 \pm 0.90$ & $7.2 \pm 0.1 ; 7$ & $6.2 \pm 0.6$ & \\
\hline Lactobacilli spp, $\log _{10} / \mathrm{g}$ feces & $8.1 \pm 0.02$ & $8.1 \pm 0.03$ & $8.1 \pm 0.03$ & $8.1 \pm 0.03$ & $8.1 \pm 0.02$ & \\
\hline Yeasts+ moulds, $\log _{10} / \mathrm{g}$ feces & $4.1 \pm 0.01$ & $4.1 \pm 0.02$ & $4.1 \pm 0.01$ & $4.1 \pm 0.02$ & $4.1 \pm 0.02$ & \\
\hline Fecal secretory IgA, mg/g & $3.4 \pm 0.1$ & $3.4 \pm 0.12$ & $3.4 \pm 0.16$ & $3.3 \pm 0.1$ & $3.4 \pm 0.14$ & \\
\hline U-HPRO- I, mg/g Creat/ kg BW & $2.3 \pm 0.22^{\mathrm{ab}}$ & $2.5 \pm 0.3$ & $2.1 \pm 0.3^{\mathrm{a}}$ & $3.4 \pm 0.34^{\mathrm{b}}$ & $1.8 \pm 0.16^{\mathrm{a}}$ & $\geq 2.5$ \\
\hline $\mathrm{U}-\mathrm{TBA}, \mathrm{mg} / \mathrm{g}$ Creat & $139 \pm 6.0$ & $138 \pm 10$ & $139 \pm 6.9$ & $149 \pm 9.6$ & $133 \pm 7.6$ & \\
\hline
\end{tabular}

Table 1: Characteristic of the children.

Mean values \pm standard error. Within the same row, mean values are significantly different $(\mathrm{P}<0.05)$, if they don't share the same alphabet (Student's $\mathrm{t}-$ test $)$. mean anthropometric indices of all children were within the norms exceeding the cutoff point of -2.0 . However, WHZ of $15.8 \%$ of the boys were $<-2.0$ denoting that they were thin for their height (wasted). Wasting represents the failure to receive adequate nutrition during the period immediately before the survey. Children less than 6 years of age tended to be slightly undernourished (WAZ $=-1.0 \pm 1.42$ ) compared to the respective mean value $(0.18 \pm 0.25)$ among those $>6$ years of

\section{Results}

The characteristics of the children are presented in Table (1). The . 
Citation: Bassuoni R, Soliman M, Hussein L, Fouad MT, Arafa MA, et al. (2019) Bio-efficiencies of Probiotic Yoghurt and Fermented Sour Sobya Supplements on Gut Microbial Health and other Associated Health Biomarkers Among Egyptian Pre-school to School Age Children. Int J Clin Nutr Diet 5: 145. doi: https:// doi.org/10.15344/2456-8171/2019/145

Page 5 of 11

age; but the difference didn't reach significant value $(\mathrm{P}>0.05)$. The stunting rate $(\mathrm{HAZ}<-2.0)$ was statistically higher among the girls $(54.4 \%)$ compared with the boys (Chi-square test $=8.28$; $\mathrm{P}<0.01$ ). The basal metabolic rate (BMR) correlated significantly with HAZ ( $\mathrm{r}$ $=0.4732 ; \mathrm{P}<0.01)$ and WHZ $(\mathrm{r}=0.5038 ; \mathrm{P}<0.01)$.

The overall diet quality expressed as healthy eating index (HEI) averaged $60.7 \pm 11.8(29.0-89.54)$ and correlated significantly with WAZ $(\mathrm{r}=0.4306 ; \mathrm{P}<0.01)$. The ideal HEI is 80 points and very low HEI has 34 points; $17 \%$ of the recorded diets had HEI between 29 up to 50 points. The HEI components scores calculated from the 3 day dietary recall showed that on daily basis, $50 \%$ of the children consumed vegetables, while only $16.7 \%$ consumed fruits. 4.3 and $12.5 \%$ of the children didn't consume any vegetables or fruits on any of the $3 \mathrm{~d}$ dietary recalls (Figure 1). The estimated daily intakes of vegetable and fruit averaged between $50 \mathrm{~g}$ and $70 \mathrm{~g}$, respectively. Half of the children consumed dairy product protein daily and different types of cheese contributed considerably. According to the HEI-2015, diets containing less than $8 \%$ saturated fatty acids per $1000 \mathrm{k}$ calories has a component score of 10 points; the respective score in the diet of our children averaged $3.15 \pm 0.48$ points. The average score for whole grains was lower in the diets of the young children $<6$ years compared with the respective value among those $\geq 6$ years (Figure 2 ). The total fat intake expressed as\% of energy intake was significantly higher $(\mathrm{P}<$ $0.05)$ among younger children $<6$ years $(35.9 \pm 1.2 \% \mathrm{EI})$ compared to the respective mean value intake $(31.0 \pm 1.15 \% \mathrm{EI})$ among children $\geq$ 6 year (Table 1). All children consumed at least one source of animal protein on all days based on $24 \mathrm{~h}$ dietary recall with mean daily intake of $19 \pm 1.5 \mathrm{~g}$ (range 1.7- $58.4 \mathrm{~g}$ ).

\section{Diet supply of vitamins and minerals}

The estimated daily intake of 8 vitamins, calcium and zinc were calculated and the results were then expressed as\% estimated average

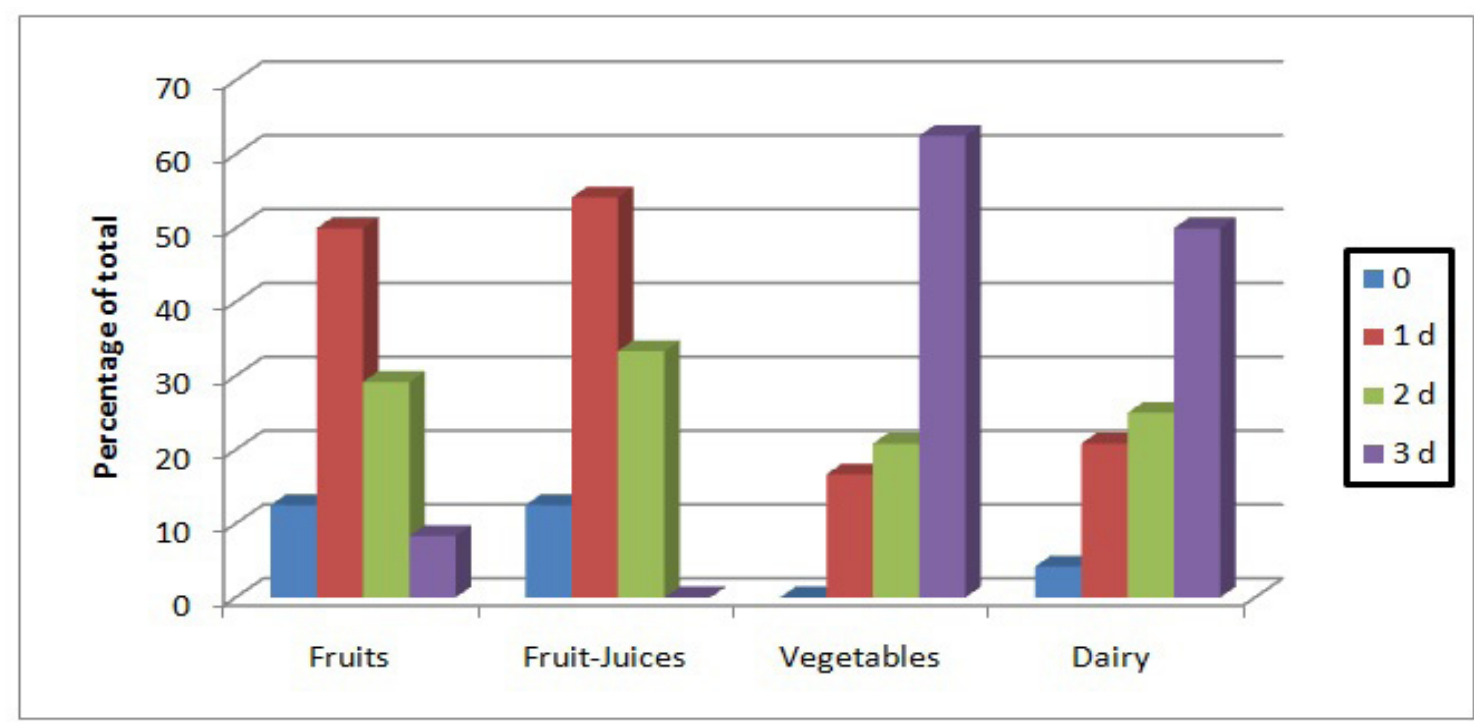

Figure 1: The percentages of children consuming fruits, fruits juices and dairy products on any day of the three $24 \mathrm{~h}$ dietary recalls.

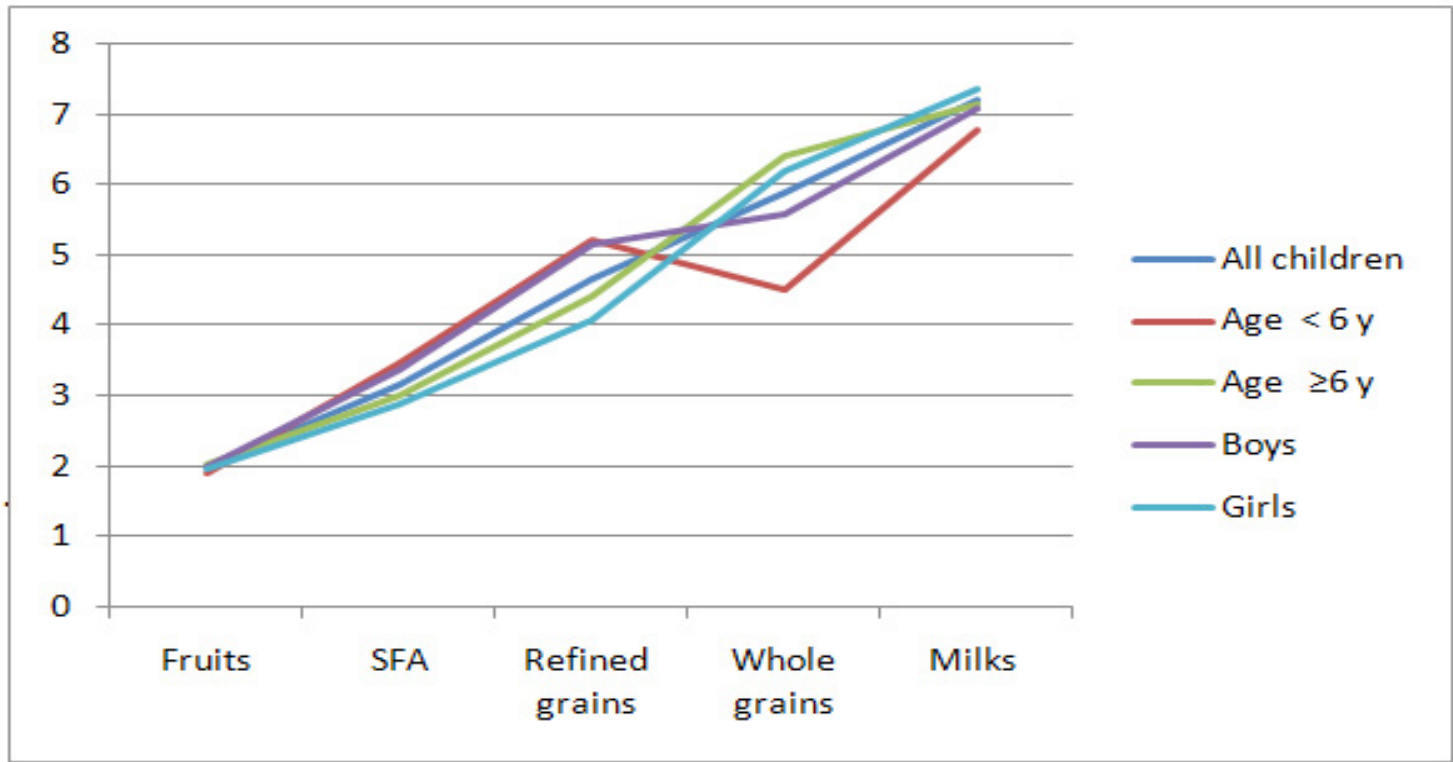

Figure 2: Healthy eating index (HEI 2015) for 5 component scores among the children classified according to gender and age groups. 
Citation: Bassuoni R, Soliman M, Hussein L, Fouad MT, Arafa MA, et al. (2019) Bio-efficiencies of Probiotic Yoghurt and Fermented Sour Sobya Supplements on Gut Microbial Health and other Associated Health Biomarkers Among Egyptian Pre-school to School Age Children. Int J Clin Nutr Diet 5: 145. doi: https:// doi.org/10.15344/2456-8171/2019/145

Page 6 of 11

requirements [FAO/WHO; 2004]. Large percentage of the children did not meet the requirements for vitamin A, B2 and for calcium intakes (Table 1). The average supply of 7 vitamins was higher in the diets of young children ( $<6$ years) compared with the respective mean values among those $\geq 6$ years.

The gut microbiota composition at baseline didn't show variations between boys and girls or age groups. Baseline mean levels of the urinary biomarkers Hydroxyproline index (U-HPRO-I) and thiobarbituric acid were also comparable between the groups (Table 1).

\section{Composition of the supplements}

Table (2) presents the chemical composition and the viable probiotic counts of the supplements. The $135 \mathrm{~g}$ daily portion of PY provided $1.4 \times 10^{9} \mathrm{cfu}$ total Bifidum bacteria. The portion size of SS (140 g daily) provided $4.2 \pm 0.62 \times 10^{9} \mathrm{cfu}$ total diverse lactic acid bacteria and $1.79 \pm 0.14 \times 10^{9} \mathrm{cfu}$ of yeast. The proteomic spectra of MALDI-TOF identified 5 out of 7 isolates as Lactobacillus rhamnosus with high score values. The API analysis identified the sobya yeast as Sacharomyces cerevisia.

\section{The effect of dietary intervention on the gut microbiota counts}

The fecal Lactobacilli counts increased 18 and 21 fold at day 21 over the respective mean baseline counts among the children consuming the PY and SS, respectively [Table 3]. No significant changes in the counts could be detected in the fecal samples of the control or the placebo groups. The mean fecal Bifidobacteria increased significantly in the feces of children consuming the Bifido probiotic yoghurt $\left(\log _{10} 7.79\right.$ up to $\log _{10} 9.3 \mathrm{cfu}$ per $\mathrm{g}$ stool). The mean yeast counts increased significantly only in the stool of children consuming the SS for 3 weeks (Table 3). The mean counts of the pathogenic bacteria Enterobacteriaceae was reduced significantly at day 21 in the feces of the children consuming PY, SS and also in the placebo group compared with the respective baseline counts (Table 3). The total anaerobic counts increased significantly in the feces of children consuming the PY or the SS, denoting richness of the gut microbiome (Table 3).

The baseline fecal secretory IgA level averaged $3.4 \pm 0.48 \mathrm{mg} / \mathrm{g}$ fecal material and increased significantly following the 3 week intervention with PY or SS $(\mathrm{P}<0.02)$, compared with the respective pre feeding levels; while their levels remained unchanged among the control and placebo groups (Table 4, Figure 3).

\begin{tabular}{|l|l|l|l|}
\hline Parameter & Placebo & Probiotic yoghurt & Sour sobya \\
\hline Portion size (Serving), g & 140 & 140 & 140 \\
\hline Total solids per serving, g & 51.5 & 18.2 & 44.2 \\
\hline Energy per serving, kcal & 233.7 & 93.8 & 193.7 \\
\hline Protein per serving, g & 7.3 & 4.9 & 2.9 \\
\hline Lipid per serving, g & 5.6 & 4.2 & 3.4 \\
\hline Carbohydrates per serving, g & 38.6 & 9.1 & 37.9 \\
\hline pH & 6.5 & 4.6 & 3.5 \\
\hline Total Bifido bacterium, $\log _{10} \mathrm{cfu}$ & & $1.4 \times 10^{9} \pm 0.01$ & nd \\
\hline Total Lactobacilli, $\log _{10} \mathrm{cfu}$ & & & $4.2 \times 10^{9} \pm 0.01$ \\
\hline Yeasts, $\log _{10} \mathrm{cfu}$ & $1.74 \pm 0.65$ & & $1.4 \times 10^{9} \pm 0.02$ \\
\hline
\end{tabular}

Table 2: Chemical composition and microbiota counts in the three dietary supplements.

\begin{tabular}{|l|l|l|l|l|l|l|l|l|}
\hline & \multicolumn{3}{l}{ Control } & \multicolumn{2}{l}{ Placebo } & \multicolumn{2}{l|}{ Probiotic yoghurt } & \multicolumn{2}{l|}{ Sour soya } \\
\hline Fecal microbiota & Day 0 & Day 21 & Day 0 & Day 21 & Day 0 & Day 21 & Day 0 & Day 21 \\
\hline \multirow{3}{*}{ Bacteroides } & $7.6 \mathrm{ab}$ & $7.39 \mathrm{a}$ & $4.88 \mathrm{bc}$ & $5.87 \mathrm{bc}$ & $6.91 \mathrm{ab}$ & $2.33 \mathrm{~cd}$ & $4.88 \mathrm{bc}$ & nd \\
\cline { 2 - 10 } & \pm 0.05 & \pm 0.05 & \pm 1.54 & \pm 1.19 & \pm 0.22 & \pm 1.22 & \pm 1.54 & \\
\hline \multirow{3}{*}{ Bifido bacterium } & $7.9 \mathrm{c}$ & $7.63 \mathrm{c}$ & $7.84 \mathrm{~cd}$ & $7.56 \mathrm{~cd}$ & $7.79 \mathrm{~d}$ & $8.83 \mathrm{a}$ & $7.87 \mathrm{~cd}$ & $7.83 \mathrm{~b}$ \\
\cline { 2 - 10 } & \pm 0.04 & \pm 0.03 & \pm 0.03 & \pm 0.04 & \pm 0.03 & \pm 0.01 & \pm 0.05 & \pm 0.05 \\
\hline Enterobacteriaceae & $7.21 \mathrm{a}$ & $7.37 \mathrm{a}$ & $7.1 \mathrm{a}$ & $4.82 \mathrm{ab}$ & $6.93 \mathrm{a}$ & $1.86 \mathrm{c}$ & $4.83 \mathrm{ab}$ & $2.97 \mathrm{bc}$ \\
\cline { 2 - 10 } & \pm 0.17 & \pm 0.07 & \pm 0.12 & \pm 1.52 & \pm 0.21 & \pm 1.18 & \pm 1.53 & \pm 1.33 \\
\hline \multirow{3}{*}{ Lactobacilli } & $8.27 \mathrm{~b}$ & $7.93 \mathrm{~b}$ & $8.13 \mathrm{~cd}$ & $7.83 \mathrm{c}$ & $8.09 \mathrm{~cd}$ & $8.92 \mathrm{a}$ & $8.07 \mathrm{~d}$ & $8.93 \mathrm{a}$ \\
\cline { 2 - 10 } & \pm 0.04 & \pm 0.03 & \pm 0.01 & \pm 0.01 & \pm 0.01 & \pm 0.01 & \pm 0.03 & \pm 0.20 \\
\hline Yeasts \& Molds & $4.11 \mathrm{~cd}$ & $4.11 \mathrm{~cd}$ & $4.17 \mathrm{~b}$ & $4.16 \mathrm{bc}$ & $4.12 \mathrm{~cd}$ & $4.09 \mathrm{~d}$ & $4.1 \mathrm{bcd}$ & $5.0 \mathrm{a}$ \\
\cline { 2 - 9 } & \pm 0.04 & \pm 0.03 & \pm 0.02 & \pm 0.01 & \pm 0.02 & \pm 0.02 & \pm 0.02 & \pm 0.02 \\
\hline Total anaerobes & 9.03 & 8.56 & 9,00 & 8.53 & 9.02 & 9.72 & 9.06 & 9.73 \\
\cline { 2 - 9 } & \pm 0.03 & \pm 0.03 & \pm 0.02 & \pm 0.02 & \pm 0.02 & \pm 0.02 & \pm 0.02 & \pm 0.02 \\
\hline
\end{tabular}

Table 3: Baseline and post feeding fecal microbiota counts $\left(\log _{10}\right.$ per $\mathrm{g}$ wet stool) excreted by the children classified according to dietary supplements.

Six children per group; Means \pm standard error; $n d=$ not determined; Mean values are significantly different $(\mathrm{P}<$ 0.05), if within the same row they don't share the same alphabet (ANOVA, Duncan test). 
Citation: Bassuoni R, Soliman M, Hussein L, Fouad MT, Arafa MA, et al. (2019) Bio-efficiencies of Probiotic Yoghurt and Fermented Sour Sobya Supplements on Gut Microbial Health and other Associated Health Biomarkers Among Egyptian Pre-school to School Age Children. Int J Clin Nutr Diet 5: 145. doi: https:// doi.org/10.15344/2456-8171/2019/145

Page 7 of 11

Baseline urinary HPRO-I averaged 2.3 (0.92 - 4.6); whereby 2/3 of all children were below the acceptable HPRO-I level for normal growth $(\geq 2.5)[35,36]$. The proportion of boys $(54 \%)$ with acceptable U-HPRO-I values were significantly higher than the respective proportion of girls (19\%) $\left(\chi^{2}=3.1, \mathrm{df}=1,0.1<\mathrm{P}>0.05\right)$.

Following the 3 week intervention with PY or SS, the urinary HPRO - I in every child belonging to both groups reached or exceeded the acceptable U-HPRO-I value of 2.5 . The mean values were significantly higher compared with the respective pre-feeding levels or to the control and the placebo (Table 4 and Figure 4). The baseline U- TBA concentration averaged $138.6 \pm 29.6 \mathrm{mg} / \mathrm{g}$ creatinine. The 3 week dietary intervention with PY or SS reduced the U-TBA concentration roughly by half the respective initial levels (Table 4, Figure 5); while the respective mean values remained almost unchanged among the control and the placebo groups.

\section{Discussion}

In recent years there has been increasing focus on improving children's diet as part of an overall strategy for preventing children under nutrition. Dietary indexes in paediatric populations is a rapidly expanding area of research because they assess nutritional adequacy and are predictive of child growth; whereby weight status is the most commonly measured health related outcome, followed by height/ length [37]. The WAZ of our children correlated significantly with age $(\mathrm{r}=0.5726 ; \mathrm{P}<0.05)$; with HEI $(\mathrm{r}=0.3821 ; \mathrm{P}<0.01)$ and with dietary animal protein intake $(r=0.2945 ; \mathrm{p}<0.05)$. HAZ correlated only with HEI $(r=0.2000, P<0.05)$. The average HEI-2015 for the diet of both children groups; $<6$ years $(62 \pm 1.6)$ and above $\geq 6$ years old $(64.16 \pm 1.33)$ were higher than the respective HEI figures of 55.3 and 51.2 reported for US child population $<6$ years and 6-11 years old, respectively [38]. In China, the developed HEI averaged 52.4 and was associated with education [39].

The high saturated fatty acids intakes $(17.8 \pm 0.94 \% \mathrm{EI})$ in the diets of our children is quite similar to that reported previously for populations from developed countries [40] and is attributed to high intakes of meat $\&$ dairy products and no sea foods. Acceptable mean level of $8.3 \pm 0.1 \%$ saturated fatty acids/EI was reported among Korean children 3-5 years old [41]. A source of animal proteins was

\begin{tabular}{|c|c|c|c|c|c|c|c|c|}
\hline \multirow[t]{2}{*}{ Parameter } & \multicolumn{2}{|l|}{ Control } & \multicolumn{2}{|l|}{ Placebo } & \multicolumn{2}{|c|}{ Probiotic yoghurt } & \multicolumn{2}{|l|}{ Sour Sobya } \\
\hline & Day 0 & Day 21 & Day 0 & Day 21 & Day 0 & Day 21 & Day 0 & Day 21 \\
\hline $\begin{array}{l}\text { Stool Ig A, mg/g } \\
\text { wet feces }\end{array}$ & $3.24 \mathrm{ef} \pm 0.16$ & $3.20 \mathrm{ef} \pm 0.13$ & $3.59 \mathrm{de} \pm 0.14$ & $4.06 c \pm 0.19$ & $2.94 \mathrm{f} \pm 0.23$ & $4.73 b \pm 0.14$ & $3.84 \mathrm{~cd} \pm 0.18$ & $5.5 \mathrm{a} \pm 0.11$ \\
\hline HPRO-I & $2.33 c \pm 0.57$ & $2.74 c \pm 0.30$ & $2.43 c \pm 0.79$ & $2.95 c \pm 0.62$ & $2.62 c \pm 0.44$ & $9.4 \mathrm{a} \pm 1.14$ & $1.95 c \pm 0.53$ & $6.77 b \pm 1.37$ \\
\hline $\begin{array}{l}\text { U-TBA, } \mu \mathrm{g} / \mathrm{g} \\
\text { creatinine }\end{array}$ & $172.0 \mathrm{a} \pm 8.44$ & $191.0 \mathrm{ab} \pm 17.91$ & $132.6 b c \pm 11.84$ & $143.0 \mathrm{~b} \pm 9.43$ & $140.7 \mathrm{~b} \pm 6.06$ & $58.1 \mathrm{~d} \pm 4.18$ & $109.1 \mathrm{c} \pm 4.36$ & $50 \mathrm{~d} \pm 9.45$ \\
\hline
\end{tabular}

Table 4: Baseline and post feeding levels of fecal secretory Ig A, urinary hydrxyproline index and thiobarbituric acid among the children classified according to dietary supplements.

Six children per group; Means \pm standard error; Mean values are significantly different $(\mathrm{P}<0.05)$, if within the same row they don't share the same alphabet (ANOVA, Duncan test).

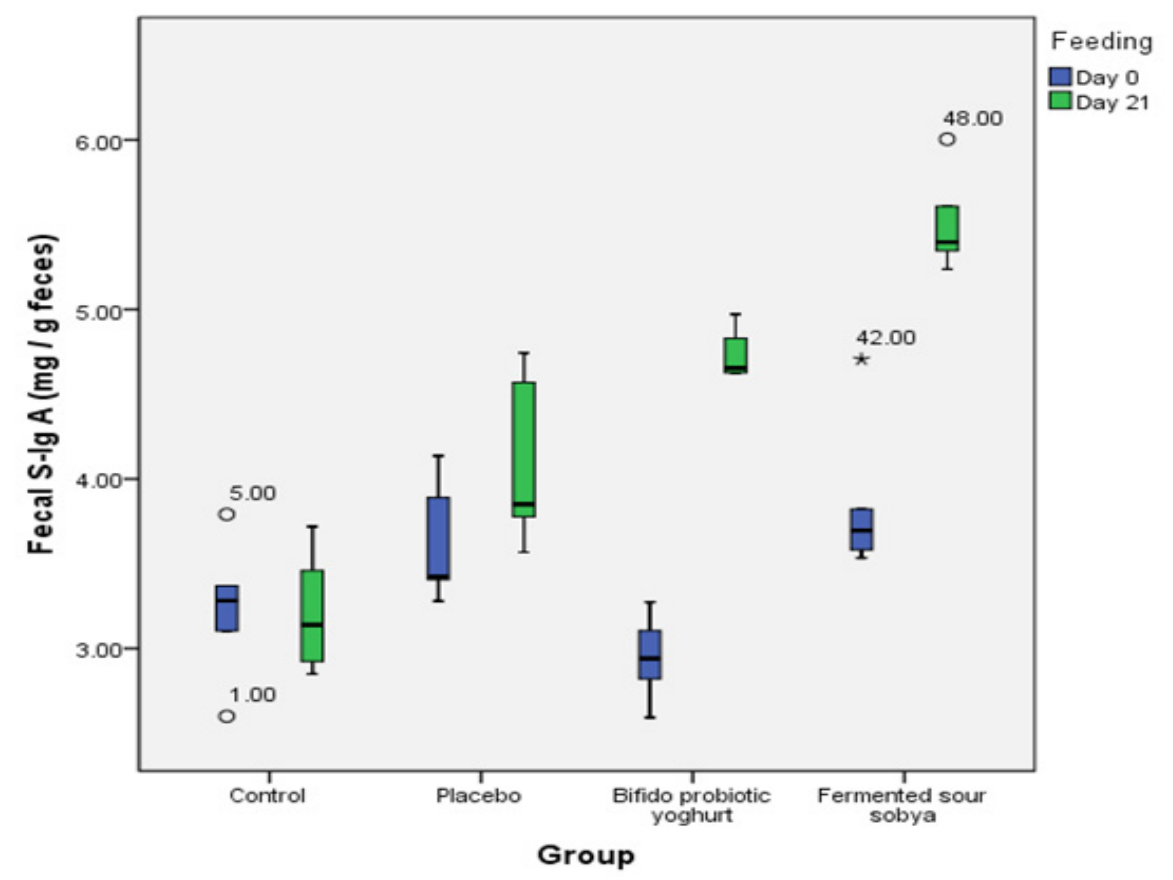

Figure 3: Whisker box plot for initial and final fecal secretory immunoglobulin A among the children distributed according to the dietary supplement. 
Citation: Bassuoni R, Soliman M, Hussein L, Fouad MT, Arafa MA, et al. (2019) Bio-efficiencies of Probiotic Yoghurt and Fermented Sour Sobya Supplements on Gut Microbial Health and other Associated Health Biomarkers Among Egyptian Pre-school to School Age Children. Int J Clin Nutr Diet 5: 145. doi: https:// doi.org/10.15344/2456-8171/2019/145

Page 8 of 11

consumed at least once daily by our children and it was reported that $3 / 4$ of the Middle Eastern region consume daily animal sourced foods (ASF) [42].

Meta analysis demonstrated that the probiotic supplement had no effect on the gain in body weights among children from developed countries, yet probiotic supplementsimproved the growth of all children from developing countries [43]. Indeed, the daily supplementation with PY or SS was associated with significant improvement in the linear growth taking the net positive increases in U-HPRO index ( $\Delta$ day 21 minus baseline values of each child) as the biomarker of growth. No such changes could be detected in the U-HPRO index values among the placebo group, though it provided $230 \mathrm{kcal}$ per day derived from rice milk porridge. Negative response was also reported among Egyptian stunted children 42 months old, who consumed daily supplement providing additional $191 \mathrm{kcal}$ derived from plant

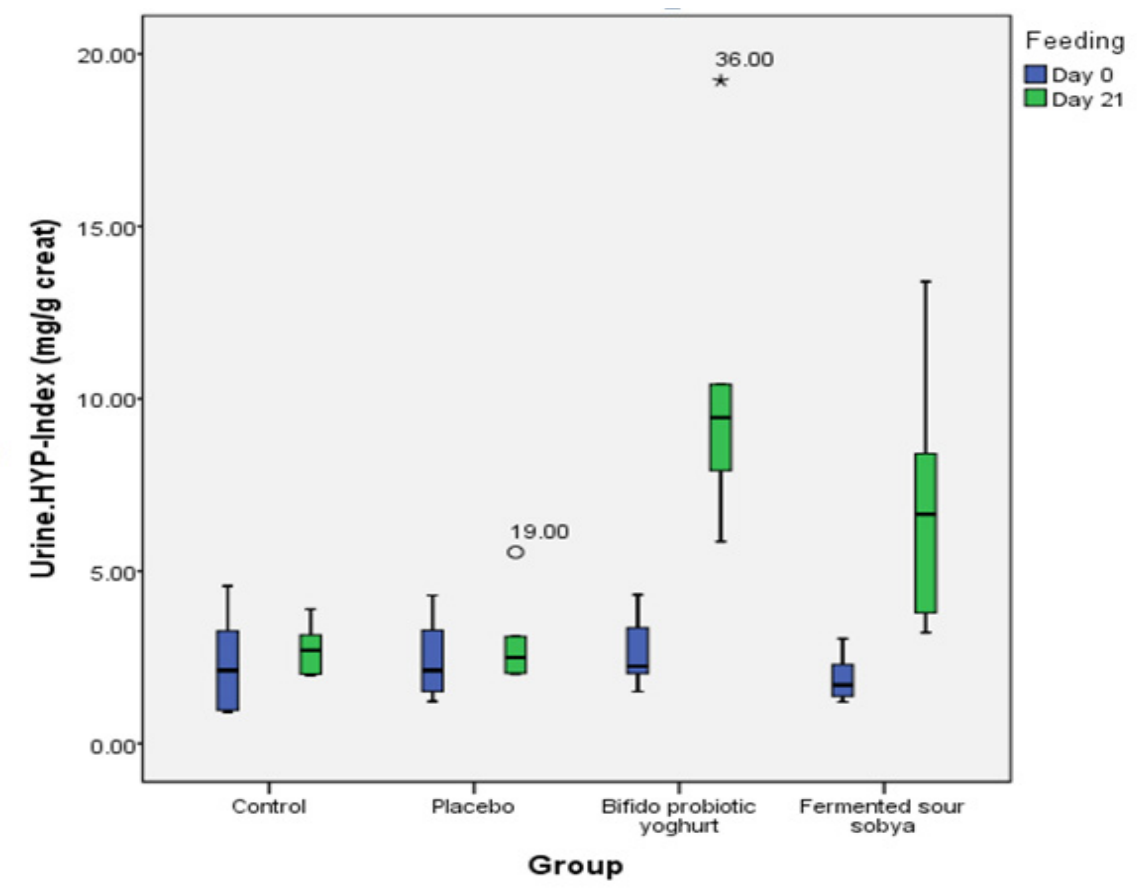

Figure 4: Whisker box plot for initial and final urinary hydroxyproline index among the children distributed according to the dietary supplement.

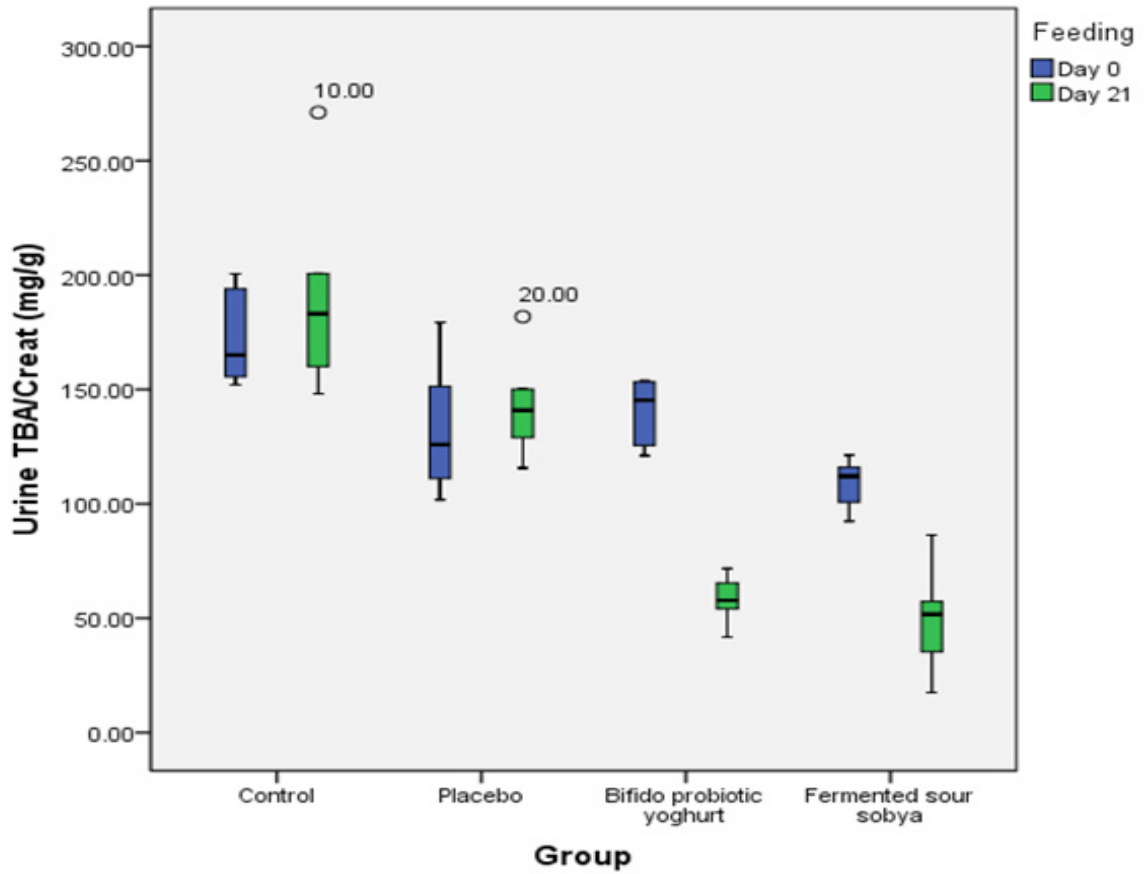

Figure 5: Whisker box plot for initial and final urinary thiobarbituric acid among the children distributed according to the dietary supplement. 
Citation: Bassuoni R, Soliman M, Hussein L, Fouad MT, Arafa MA, et al. (2019) Bio-efficiencies of Probiotic Yoghurt and Fermented Sour Sobya Supplements on Gut Microbial Health and other Associated Health Biomarkers Among Egyptian Pre-school to School Age Children. Int J Clin Nutr Diet 5: 145. doi: https:// doi.org/10.15344/2456-8171/2019/145

Page 9 of 11

formula consisting of sesame: dates: dried apricots: coconut: peanut and cocoa in the proportions of 30:20: 20: 15: 10: 5 weight percent. The criteria of response was HAZ and serum ferritin didn't differ at the end of the 8 week supplementation compared to that of the respective placebo group based on sugar syrup [44].

It is hypothesized that infection by pathogenic Enterobacter bacteria has negative impact on demarcated variations in the gut health which impair growth. This hypothesis is supported in the present study by the existence of high significant negative correlation coefficient $(\mathrm{r}$ $=-0.4454 ; \mathrm{P}<0.01)$ between the net increases in the U- HPRO-I ( $\Delta$ day 21 minus baseline value of each child) and the respective net decreases in the fecal count of $\log _{10}$ Enterobacteriaceae ( $\Delta$ day 21 minus baseline values of each child). Such relation could not be detected by anthropometric measurements, denoting the usefulness of HPRO-I biomarker before growth spurt could be detected by anthropometry in the response in growth rate over short periods of time and in close monitoring of treatment regimens. The availability of potential biomarkers with high prognostic value to assist in making the prospect of catch-up growth in poor settings has high priority [45]. Hydroxy proline [HPRO] is a collagen-related marker, since it is present in all fibrillar collagens and tissue breakdown contribute to urinary HPRO [46]. Mean HPRO-I of $2.5 \pm 0.9$ and $1.6 \pm 0.6$ were reported among healthy well-nourished and in under-weight children, respectively [35-36].

Reestablishing microbiota-mediated colonization resistance (CR) by the administration of potential probiotics could markedly develop immune response for healthy gut microbiota, which disfavor colonization of enteric pathogens and reduce infections, particularly those caused by antibiotic-resistant bacteria [47].

The increase in fecal Lactobacilli counts following the 3 week intake of PY $(16.3 \pm 0.24 \%)$ or the SS $(16.7 \pm 0.24 \%)$ confirmed previous reports that Lactobaccilli survive the gastric transit and reach the gut. Higher \% recoveries of Lactobaccilli were detected in the feces ranging from $28.4 \%$ of Lactobacillus casei DN - 114 after a dosage of $\log 10^{9} \mathrm{cfu}$ [48] up to 1000 fold excess specific L. rhamnosusrelated bacteria after dosage of $1.55 \times 10^{10} \mathrm{cfu}$ L rhamnosus GG [49] The fecal Lactobacilli and its ratio to the total anaerobic bacteria are typically used as an indicator of healthy gut [50].

The increases in fecal Bifidobacteria output during the PY period was associated with reduction in the urinary TBARS concentrations indicating potential anti-oxidative activities of Bifidobacterium. This finding is in good agreement with previous report on the reducing concentrations of fecal TBARS following consumption of Bifidobacterium bifidum or Lactobacillus acidophilus yoghurt med by Iranian adults [51].

The gut microbiota plays major role in regulating mucosal and systemic immunity and it is estimated that roughly $3 / 4$ of the colon anaerobic bacteria is coated with secretory immunoglobulin A (s-Ig A) in absence of colonic mucosal inflammation [52]. The significant increases in fecal S-Ig A concentration following the 3 week dietary intervention with PY or SS are in good agreement with previous reports showing that 3 week probiotic supplementation increased fecal secretory IgA concentrations in preterm infants [53]. This unique probiotic property has implication on their potential role in preventing gastrointestinal infections and lowering respiratory tract infections [54].
The urinary thiobarbituric acid (U-TBA) is formed by the reaction with malondialdehyde (MDA) of lipids and is a biomarker of the oxidative stress [55] and the excessive free radicals so generated would have the potential to cause enormous pathological damage. In the present study the 3 week supplementation with PY or SS successfully reduced the concentration of urinary TBA roughly to half the respective initial concentrations; suggesting that probiotic bacteria inhibited the excessive generated free radicals. This finding supports the results reported previously on adolescents demonstrating the potential anti oxidative activity of probiotic yoghurt and SS [20].

Lactobacillus rhamnosus Yoba 2012 is the world's first generic probiotic strain formulated by culturing Western probiotic $L$. rhamnosus GG with Streptococcus thermophilus to optimize synergistic propagation of both strains in wide range of fermented food matrices with shelf life viability of 2 years [56].

\section{Conclusion and Recommendations}

A monitoring and evaluation framework, operational and technical guidance as well as program tools for nutrition is urgently needed for giving high priority to food safety unit and research area of lactic acid fermentation as a technique to reduce the risk of having pathogenic microorganisms grow in the food.

Developments of novel traditional fermented foods containing endogenous probiotic strains particularly from cereal origin at low cost and retain good viability/ survival in the product during storage to up regulate disordered intestinal function and re-establish gutmicrobial balance.

The expansion in conducting well controlled randomized controlled trials to define and optimize several issues and mechanistic studies of relevance to probiotic functionalities on up regulating the gut-microbial balance.

\section{Competing Interests}

The authors declare that they have no competing interests.

\section{Authors' contributions}

$\mathrm{RB}$ recruited the children and was responsible for conducting the randomized controlled trial, collecting the stool and urine samples, sharing in the microbiological examinations and chemical analysis. MS was responsible for the chemical analysis of the biological fluids and the immunological assays of the stool. LH designed the concept of the study, carried out the statistical analysis and wrote the manuscript. MT was responsible for the microbiological of the supplements and the stool samples; MA shared in the microbiological examinations of the samples. AA shared in the conceptualization of the study and the design of the study.

\section{Acknowledgment}

The authors are grateful to the participants and their mothers, who without their cooperation this study could not be completed. Also thanks to Dr Hesham Abdel Latif, Faculty of Agriculture, Cairo university for the ANOVA analysis. 
Citation: Bassuoni R, Soliman M, Hussein L, Fouad MT, Arafa MA, et al. (2019) Bio-efficiencies of Probiotic Yoghurt and Fermented Sour Sobya Supplements on Gut Microbial Health and other Associated Health Biomarkers Among Egyptian Pre-school to School Age Children. Int J Clin Nutr Diet 5: 145. doi: https:// doi.org/10.15344/2456-8171/2019/145

Page 10 of 11

\section{References}

1. UNICEF, WHO, the World Bank Group (2019) Levels and trends in child malnutrition. WHO Geneva.

2. The Sustainable Development Goals (SDG 2030) Report. The United Nation, NY.

3. Mohammad MA, Hussein L, Coward A, Jackson S (2007) Prevalence of Helicobacter pylori infection among Egyptian Children: Impact of socia background and effect on growth. Public Health Nutr 11: 230-236.

4. Mohamed MA, Hussein L, Yamama G, El-Rawy S (2007) The Impact of probiotic and honey on the gut barrier function among Egyptian children. J Nutr Environm Medicine 16: 10-15.

5. Dror DK, Allen LH (2011) The importance of milk and other animal-source foods for children in low-income countries. Food Nutr Bull 32: 227 - 243.

6. Batra P, Schlossman N, Balan I, Pruzensky W, Balan A, et al. (2016) A randomized controlled trial of higher- compared with lower-dairy second meals daily in preschools in Guinea-Bissau demonstrates an attendancedependent increase in weight gain for both meal types and an increase in mid-upper arm circumference for the higher-dairy meal. J Nutr 146: 124 132.

7. Baum JI, Miller JD, Gai BL (2017) The effect of egg supplementation on growth parameters in children participating in a school feeding program in rural Uganda: A pilot study. Food Nutr Res 61: 1-6.

8. Hussein L, Ezzilarab A (1994) The frequency distribution of lactose malabsorption among adult populations from the Eastern and Western Egyptian deserts. Biochem Genetics 32: 331-342.

9. Fijan S (2014) Microorganisms with claimed probiotic properties: An overview of recent literature. Int J Environ Res Public Health 11: 4745-4767.

10. FAO Probiotics in food (2001) FAO food and Nutrition paper, Rome, Ita ly.

11. Bertazzoni E, Donelli G, Midtvedt T, Nicoli J, Sanz Y, et al. (2013) Probiotics and clinical effects: Is the number what counts? J Chemother 25: 193-212.

12. Derrien M, Vlieg JET (2015) Fate, activity and impact of ingested bacteria within the human gut microbiota. Trends Microbiol 23: 355-367.

13. Dodooa CC, Wanga J, Basita AW, Stapletona P, Gaisforda S, et al. (2017) Targeted delivery of probiotics to enhance gastrointestinal stability and intestinal colonization. Intern J Pharmac 530: 224-229.

14. Kolaček S, Hojsak I, Berni Canani R, Guarino A, Indrio F, et al. (2017) Commercial probiotic products: A call for improved quality control. A position paper by the ESPGHAN working 124 group for probiotics and prebiotics. J Pediatr Gastroenterol Nutr 65: 117.

15. Tamang JP, Shin DH, Jung SJ, Chae SW (2016) Functional properties of microorganisms in fermented foods. Frontiers Microbiol 7: 578-590.

16. BCC Research Report (2018) The probiotics market, Ingredients, Supplements, Foods.

17. FAO Traditional fermented foods and beverages for improved livelihood (2011) FAO Diversification Booklet 21: 85.

18. Gassem MAA (2002) A microbiological study of Sobia: a fermented beverage in the Western province of Saudi Arabia. World J Microbiol Biotechnol 18: 173

19. Fouad MT, Amr M, Hussein L, Romeilah R, Gouda M, et al. (2015) In-Vitro antioxidant and antimicrobial activities of selected fruit and vegetable juices and fermented dairy products commonly consumed in Egypt. J Pharmac Biol Chem Sc 6: 541-550.

20. Hussein L, Gouda M, Fouad M, Labib E, Bassyouni R, et al. (2014) Dietary intervention with yoghurt, symbiotic yogurt or traditional fermented sobya: Bio-potency among male adolescents using five bio-markers of relevance to colonic metabolic activities. Food Nutr Sci 5: 1131-1144.

21. WHO (2006) Child growth standards.

22. Schofield WN, Schofield C, James WPT (1985) Basal metabolic rate. Human Nutr: Clin Nutr 1: 1-96.

23. Krebs-Smith SM, Pannucci TE, Subar AF, Kirkpatrick S, Lerman J, et al. (2018) Update of the healthy eating index: HEI-2015. J AcadNutr Diet 118: 15911602.

24. FAO/WHO (2004) Human Vitamin and Mineral Requirements. Food and Nutrition Division, FAO Rome.
25. Antunes AEC, Grael ET, Moreno I, Rodrigues LG, Dourado FM, et al. (2007) Selective numeration and viability of Bifidobacterium animalis Subsp Lactis in a new fermented milk product. Brazilian J Microbiol 38: 173-177.

26. Pintado ME, Da Silva JAL, Fernandes PB, Malcata X, Hogg TA (1996) Microbiological and rheological studies on Portuguese kefir grains. InternJ Food ScTechnol 31: 15-26.

27. Labib E, Blaut M, Hussein L, Gouda M, Kramer DL, et al. (2018) Molecular diversity of gut microbiota and short chain fatty acids in Egyptian adults following dietary intervention with fermented sobya. J Food Microbiol Saf Hyg 3: 139- 150.

28. Schumann P, Maier T (2014) MALDI-TOF mass spectroscopy applied to classification and identification of bacteria. Methods Microbiol 41: 275-306.

29. Soro-Yao AA, Schumann P, Thonart P, Dje KM, Pukall R, et al. (2014) The use of MALDI-TOF mass spectrometry, ribotyping and phenotypic tests to identify lactic acid bacteria from fermented cereal foods in Abidjan (Cote d'Ivoire). Open Microbiol J 8: 78-86.

30. Beerens $\mathrm{H}$ (1990) An elective and selective medium for Bifidobacterium spp. Lett Appl Microbiol 11: 155-157.

31. Hartemink R, Domenech VR, Rombouts FM (1997) LAMVAB - a new selective medium for the isolation of lactobacilli from faeces. J Microbiol Methods 29: 77-84.

32. Gordeladze JO, Halse J, Djoseland O, Haugen HN (1978) A simple procedure for the determination of hydroxyproline in urine and bone. Biochemical Medicine 20: 23-30.

33. Jaffe $M$ (1986) Uber den niederschlag, welchen Pikrinsaure in normalen Harn erzeugt und uber eine neue Reaction des Kreatinins. Z Physiol Chem 10: 391-400.

34. Delanghe JR, Speeckaert MM (2011) Creatinine determination according to Jaffe-what does it stand for? NDT Plus 4: 83-86.

35. Ohkawa H, Ohishi N, Yagi K (1979) Assay for lipid peroxides in animal tissues by thiobarbituric acid reaction. Anal Biochem 95: 351-358.

36. Whitehead RJ (1965) Hydroxyproline creatinine ratio as an index of nutritional status and rate of growth. Lancet 18: 567- 570 .

37. Wharton BA, Gough G, Williams A, Kitts S, Pennock CA et al. (1972) Urinary total hydroxyproline: creatinine ratio. Range of normal and clinical application in British children. Arch Dis Child 47: 74-79.

38. Marshal S, Burrows T, Collins CE (2014) Systematic review of diet quality indices and their associations with health-related outcomes in children and adolescents. J Human Nutr Diet 27: 577-598.

39. Gu X, Tucker KL (2017) Dietary quality of the US child and adolescent population: trends from 1999 to 2012 and associations with the use of federal nutrition assistance programs. Am J Clin Nutr 105: 194-202.

40. Yuan YQ, Li F, Dong RH, Chen JS, He GS, et al. (2017) The development of a Chinese healthy eating index and its application in the general population. Nutrients 9: 977.

41. Harika RK, Eilander A, Alssema M, Osendarp SJM, Zock PL, et al. (2013) Intake of fatty acids in general populations worldwide does not meet dietary recommendations to prevent coronary heart disease: A systematic review of data from 40 countries. Ann Nutr Metab 63: 229-238.

42. Baek YJ, Shim JE, Song S (2018) Dietary intake of fat and fatty acids by 1-5-year-old children in Korea: a cross-sectional study based on data from the sixth Korea National Health and Nutrition Examination Survey. Nutrition Research Practice 12: 324-335.

43. Headey D, Hirvonen K, Hoddinott J (2018) Animal sourced foods and child stunting. Am J Agric Ecol 100: 1302-1319.

44. El Eskafy AMI (2008) Improving the nutritional status of preschool children in El-Menoufiia governorate, Egypt. Doctor disseratation, Univ Giessen Germany.

45. Onubi OJ, Poobalan AS, Dineen B, Marais D, McNeill G, et al. (2015) Effects of probiotics on child growth: a systematic review. J Health popul Nutr 34: 8- 22.

46. Prentice AM (2016) Applications of nutritional biomarkers in global health settings. In: Next-Generation Nutritional Biomarkers to Guide Better Health Care. Baetge EE, Dhawan A, Prentice AM: Nestlé NutrInst Workshop 84: 15 23.

47. Seibel MJ (2005) Biochemical markers of bone turnover Part I: Biochemistry and variability. Clin Biochem Rev 26: 97-122.

48. Sorbara MT, Pamer EG (2019) Interbacterial mechanisms of colonization resistance and the strategies pathogens use to overcome them. Mucosa Immunol 12: 1-9. 
Citation: Bassuoni R, Soliman M, Hussein L, Fouad MT, Arafa MA, et al. (2019) Bio-efficiencies of Probiotic Yoghurt and Fermented Sour Sobya Supplements on Gut Microbial Health and other Associated Health Biomarkers Among Egyptian Pre-school to School Age Children. Int J Clin Nutr Diet 5: 145. doi: https:// doi.org/10.15344/2456-8171/2019/145

Page 11 of 11

49. Oozeer R, Leplingard A, Mater DDG, Mogenet A, Michelin R, et al (2006) Survival of Lactobacillus casei in the human digestive tract after consumption of fermented milk. Appl Environ Microbiol 72: 5615-5617.

50. Lahti L, Salonen A, Kekkonen RA, Salojarvi J, Jalanka-Tuovinen J, et al. (2013) Associations between the human intestinal microbiota, Lactobacillus rhamnosus GG and serum lipids indicated by integrated analysis of highthroughput profiling data. Peer J 1: 32.

51. Goldin BR, Gorbach SL, Saxelin M, Barakat S, Gualtieri L, et al. (1992) Survival of Lactobacillus species (strain GG) in human gastrointestinal tract. Dig Dis Sci 37: 121-128.

52. Niazmand R, Sarabi M, Arabporiani NA (2010) Effect of bioyogurt consumption on fatty metabolites of serum and colonic microflora in healthy subjects. J Agr Sci Tech 12: 597-603.

53. Stecher B (2015) The Roles of inflammation, nutrient availability and the commensal microbiota in enteric pathogen infection. Microbiol Spectr.

54. van der Waaij LA, Limburg PC, Mesander G, van der Waaij D (1996) In vivo IgA coating of anaerobic bacteria in human faeces. Gut 38: 348- 354.

55. Mohan R, Koebnick C, Schildt J, Mueller M, Radke M, et al. (2008) Effects of Bifidobacteriumlactis Bb12 supplementation on body weight, fecal $\mathrm{pH}$ acetate, lactate, calprotectin, and IgA in preterm infants. Pediatr Res 64 418- 422.

56. Kabeerdoss J, Devi RS, Mary RR, Prabhavathi D, Vidya R, et al. (2011) Effect of yoghurt containing Bifidobacterium lactis $\mathrm{Bb} 12 \AA$ on faecal excretion of secretory immunoglobulin $A$ and human beta-defensin 2 in healthy adult volunteers. Nutr J 10: 138-141.

57. Mayne S (2003) Antioxidant nutrients and chronic disease: Use of Biomarkers of exposure and oxidative stress status in epidemiologic research. J Nutr 133: 933-940.

58. Kort R, Westerik N, Mariela Serrano L, Douillard FP, Gottstein W, et al (2015) A novel consortium of Lactobacillus rhamnosus and Streptococcus thermophilus for increased access to functional fermented foods. Microb Cell Fact 14: 195. 